\title{
Seed preservatives properties of Secamone afzelii (Schult) K. Schum extracts on wheat grains damage and germination capability
}

\author{
J. M. Adesina* (1) and A. T. B. Aderibigbe
}

\begin{abstract}
Background: Botanical pesticides may be a possible solution to the post-harvest loss of stored grains faced by farmers and food processors. In this study, seed preservatives properties of Secamone afzelii leaves extracts at 50, 100, 150, $200 \mu$ l concentrations were investigated against lesser grain borer Rhyzopertha dominica (Fabricus) infestation on wheat grains weight loss and seed germination capability arranged in a Completely Randomized Design (CRD) and replicated thrice under ambient laboratory conditions.

Results: The outcomes of the study showed that $S$. afzelii leaves extracts exhibited significant effect $(p<0.05)$ in suppressing R. dominica adult emergence and weight loss of wheat grains than untreated. The increase in the concentrations led to significant decrease in adult emergence and weight loss with different extracts. Secamone afzelii ethyl acetate and hexane extracts significantly subdued adult emergence in contact toxicity (6.69\% and $8.49 \%)$ and fumigant toxicity (8.85 and 8.87); a similar trend was observed in weight loss in both contact (2.33\% and 5.13\%) and fumigant (1.50\% and 1.03\%) toxicities at $200 \mu$, respectively. None of the extracts hinder the germination of treated grains, while germination percentage ranged between $88.69 \%$ and $93.40 \%$.

Conclusion: The results clearly indicated that $S$. afzelii extracts, in general, ethyl acetate and hexane extracts of $S$. afzelii in particular were the best seed preservative for stored wheat. Thus $S$. afzelii leaves extracts could be utilized as grain protectant substitute for conventional synthetic insecticides and fumigants in the control of insect infestation and conservation of stored grain quality and germination capability. Further study is required to identify the bioactive chemicals responsible for the $S$. afzelii extracts insecticidal activity and stored grains quality preservation.
\end{abstract}

Keywords: Germination capability, Germination rate, Post-harvest loss, Seed preservatives, Wheat grains

\section{Background}

A number of insect pests induced deleterious effects on cereal grains/seeds post-harvest management. Among the key insect pests of stored cereal grains are the coleopteran beetles, namely: Granary weevil, Sitophilus granarius (Linnaeus), maize weevil, S. zeamais (Motschulsky), rice weevil S. oryzae (Linnaeus), red flour beetle, Tribolium castaneum (Herbst), Angoumois grain moth, Sitotroga cerealella (Olivier) and Lesser grain borer,

\footnotetext{
*Correspondence: mobolade72@gmail.com

Department of Crop, Soil and Pest Management Technology, Rufus Giwa Polytechnic, P. M. B. 1019, Owo, Ondo State, Nigeria
}

Rhyzopertha dominica (Fabricus), and cause substantial grains perforation or damage, weight loss, alteration of nutritional quality, decreased germination potential and leading to colossal economic losses due to reduction in the marketable worth of the seed (Adesina et al. 2019a, b, 2020; Adesina and Mobolade-Adesina 2020).

To protect stored cereal grains against storage insect infestation in storage facilities such as granaries, warehouse/storeroom, rhumbus or silo, since it is practically impossible to store food grains/seeds without insect attack, countless number of synthetic insecticides and fumigants remains the conceivable key to the prevention 
of post-harvest loss of wheat and other stored food grains faced by farmers, food grains merchants and processors.

In spite of the effectiveness of synthetic insecticides and fumigants, its uses have faced serious challenges such as increased insecticide residues on stored grains, which pose health threats to human, development of resistant strains and pest resurgence and ecological disorder (Tesfu and Emana 2013; Khaliq et al. 2014).

Therefore, there is a concerted effort to seek and developed substitute to synthetic insecticides and fumigants to keep stored seed/food grains free of insect pest infestations and for long-term storability and quality parameter maintenance. The use of plant products as botanical pesticides is projected as the most sustainable and ecologically safe tactic to counterbalance the constantly cumulative threat posed by conventional insecticides.

It has been reported that several botanical extracts have the ability of causing negative impact on insect pests (Kestenholz et al. 2007). These extracts have a lot of advantages like readily available and affordable, relatively inoffensive to the environment and to man and offer no residual effects, easy degradable and selective to the targeted pests (Khan et al 2010; Ntonifor et al 2010). In this background, several plant products have been evaluated and considered encouraging in the prevention of stored grain damage and sustenance of seed germination quality.

From available literature, no scientific report of $S$. afzelii products as insecticide against stored wheat insect pests was documented. However, the insecticidal activity of the plant methanol and hexane extracts was effective against Callosobruchus maculatus (Adesina and Ofuya 2015). Therefore, this study forms part of the search for bioinsecticides for the management of destructive pests of stored wheat grain products against grain damage and germination capabilities with extracts of S. afzelii as the main focus.

\section{Methods}

\section{Study location and conditions}

The experiment was laid out in a Completely Randomized Design (CRD) and replicated thrice in the Pest Management Laboratory, Department of Crop, Pest Management Technology, Rufus Giwa Polytechnic, Owo, Ondo State, Nigeria, under ambient laboratory conditions of $32 \pm 2{ }^{\circ} \mathrm{C}$ temperature, $75 \pm 5 \%$ relative humidity and 12-h dark/light photoperiods.

\section{Rearing insect culture}

Adults $R$. dominica were obtained from infested wheat grains bought from Ulede market, Owo, Ondo State, Nigeria. Insects were subsequently mass nurtured on whole clean, intact and disinfested wheat in 5-L plastic jars covered with muslin cloth and tightly secured with rubber band. This was done by weighing $4 \mathrm{~kg}$ of wheat grains into clean plastic jars and was infested with about 150 mixed sex adults of $R$. dominica and maintained in the laboratory for mass culture under a temperature of $32 \pm 2{ }^{\circ} \mathrm{C}, 75 \pm 5 \%$ relative humidity and 12 -L: 12D photoregime. This culture was maintained and used as source of $R$. dominica for all bioassays, and insects of mixed sex required for these trials were 2-4 days old.

\section{Preparation of S. afzelii leaves extracts}

Mature vines of $S$. afzelii were collected from Laoso Camp in Ondo, Nigeria. The leaves were identified at the Department of Forestry and Wood Technology, Rufus Giwa Polytechnic, Owo, Ondo State, Nigeria. The leaves were detached and air-dried in a cool dry place for three weeks. The dried leaves were then pulverized into a powder using hammer mill. Thereafter, about $300 \mathrm{~g}$ of S. afzelii leaves powder was extracted by separately soaking in an extraction bottle containing $500 \mathrm{ml}$ of hexane, ethyl acetate, acetone and methanol respectively for $48 \mathrm{~h}$, occasionally stirred with a glass rod in order to ensure uniformity in extraction. The extracts were strained through a double-layer Whatman's No. 1 filter paper followed by evaporation until the solvent was dried. The crude extracts were stored in vial bottles and stored in the refrigerator for subsequent insecticidal activities by contact and fumigant toxicity (Ileke et al. 2016; Adesina and Mobolade-Adesina 2020; Ileke 2021).

\section{Contact and fumigant toxicity insect bioassay}

About $20 \mathrm{~g}$ of the disinfected wheat grains was weighed into each Petri dishes and desiccators for contact and fumigant bioassay, respectively. For contact toxicity, wheat grains were treated with 50, 100150 and $200 \mu \mathrm{l}$ in triplicates of hexane, ethyl acetate, acetone and methanol extracts of S. afzelii in 250-ml plastic dishes using a micropipette. To ensure even mixing of the extracts with the grains, treated grains were thoroughly mixed using a glass rod and then the grains were left to air-dried for about $15 \mathrm{~min}$. After drying of the grains, ten unsexed 2-4-day-old adult $R$. dominica were introduced into each Petri dish. There was also a control treatment containing untreated seeds.

In fumigant toxicity, 10 unsexed 2-4-day-old adult $R$. dominica was exposed to 50,100, 150 and $200 \mu \mathrm{l}$ of hexane, ethyl acetate, acetone and methanol S. afzelii extracts in 0.85-1-L desiccators containing $20 \mathrm{~g}$ of wheat grains that served as the fumigation chambers with a Whatman No. 1 filter circle ( $9 \mathrm{~cm}$ size) placed to serve as an evaporating surface for injecting extracts with a micropipette (Adesina et al. 2018). From both experiments, the adult mortality count was recorded for 5 days after infestation and all insects both dead and live were 
removed. At 45 days after treatment, number of emerging adult insects in each contact and fumigant toxicity and control were recorded.

The weight loss of wheat grains in the treated and control groups was calculated after 45 days of infestation on a fresh weight basis according to Parkin (1956) formula: $W I-W / W I \times 100$, where $W I$ is the weight of the grains before the experiment and $W$ is the weight of the grains at the end of the experiment.

\section{Seed germination test}

The effect of S. afzelii extracts on germination of treated wheat samples was determined following the method of Adesina et al (2019a). Damaged and undamaged grains carefully separated, $20 \mathrm{~g}$ of wheat grains in each of the fumigated and contact toxicities groups were randomly selected from the undamaged ones and placed on moistened tissue paper in sterilized Petri plates as the growth medium and allowed to germinate at room temperature. The germination percentage in fumigated and contact toxicities groups was determined after $24 \mathrm{~h}$. Three replicates were conducted for each sample group. The number of germinated seeds in each treated and control was recorded for all the replicates, and the percent germination was determined (Demissie et al. 2008; Manmathan and Lapitan 2013).

\section{Statistical analysis}

Data obtained from the study were recorded as mean value $\pm S E$ and subjected to analysis of variance (ANOVA) after the proper transformation, and there were a significant treatment means, Tukey's Student test (HSD) was used to identify differences in treatment means at $5 \%$ probability level of significance. All collected data were statistically analyzed using SPSS version 11.5 software.

\section{Results}

\section{Effect of Secamone afzelii extracts on percentage adult emergence}

The results presented in Table 1 show that $S$. afzelii extracts were effective in suppressing adult emergence and reducing the population increase of $R$. dominica compared to the untreated control and the level of adult emergence from the treated grains varied with the extracts and concentrations applied. In wheat grains treated with $S$. afzelii extracts at its highest concentrations $(200 \mu \mathrm{l} / 20 \mathrm{~g}$ wheat), a total range of 10.26-6.69 adult $R$. dominica insect emergence was recorded, while $S$. afzelii ethyl acetate extracts at its highest concentration recorded the lowest (6.69) adult $R$. dominica emergence. The lowest suppression of $R$. dominica population in grains treated with the extracts was observed at its
Table 1 Effect of Secamone afzelii extracts on percentage adult emergence

\begin{tabular}{lllll}
\hline $\begin{array}{l}\text { Contact } \\
\text { toxicity }\end{array}$ & \multicolumn{2}{l}{ Concentration $(\boldsymbol{\mu l})$} & & \\
\hline $\begin{array}{l}\text { Treatments } \\
\text { Control }\end{array}$ & 20 & 100 & 150 & 200 \\
Hexane & $26.23 \pm 2.12 \mathrm{a}$ & $19.66 \pm 2.04 \mathrm{~b}$ & $13.16 \pm 1.37 \mathrm{c}$ & $8.49 \pm 1.55 \mathrm{~b}$ \\
Ethyl acetate & $23.63 \pm 1,38 \mathrm{~b}$ & $20.83 \pm 1.73 \mathrm{~b}$ & $15.28 \pm 2.66 \mathrm{~b}$ & $6.69 \pm 1.03 \mathrm{c}$ \\
Methanol & $20.23 \pm 1.78 \mathrm{c}$ & $15.81 \pm 1.62 \mathrm{c}$ & $11.81 \pm 1.84 \mathrm{~d}$ & $9.36 \pm 2.31 \mathrm{~b}$ \\
Acetone & $24.33 \pm 2.91 \mathrm{~b}$ & $16.42 \pm 1.05 \mathrm{c}$ & $13.81 \pm 2.96 \mathrm{c}$ & $10.26 \pm 1.88 \mathrm{~b}$ \\
Fumigant toxicity & & & \\
Control & $31.49 \pm 2.88 \mathrm{a}$ & $38.09 \pm 1.46 \mathrm{a}$ & $34.40 \pm 1.81 \mathrm{a}$ & $30.87 \pm 2.55 \mathrm{a}$ \\
Hexane & $20.38 \pm 2.61 \mathrm{c}$ & $15.34 \pm 1.98 \mathrm{c}$ & $14.70 \pm 2.06 \mathrm{c}$ & $8.85 \pm 1.50 \mathrm{c}$ \\
Ethyl acetate & $28.67 \pm 0.03 \mathrm{~b}$ & $25.00 \pm 3.80 \mathrm{~b}$ & $21.75 \pm 0.30 \mathrm{~b}$ & $8.87 \pm 1.30 \mathrm{c}$ \\
Methanol & $27.09 \pm 2.40 \mathrm{~b}$ & $23.69 \pm 4.60 \mathrm{bc}$ & $17.27 \pm 1.86 \mathrm{c}$ & $10.74 \pm 3.25 \mathrm{~b}$ \\
Acetone & $28.86 \pm 1.73 \mathrm{~b}$ & $20.84 \pm 0.81 \mathrm{bc}$ & $18.55 \pm 1.32 \mathrm{c}$ & $11.68 \pm 1.38 \mathrm{~b}$ \\
\hline
\end{tabular}

Means within a column followed by different letters are significantly different $(P>0.05 \%)$, Tukey's Student test (HSD)

Table 2 Effect of Secamone afzelii extracts on percentage weight loss

\begin{tabular}{lllll}
\hline $\begin{array}{l}\text { Contact } \\
\text { toxicity }\end{array}$ & Concentration $(\boldsymbol{\mu l})$ & & \\
\hline Treatments & 50 & 100 & 150 & 200 \\
Control & $28.93 \pm 3.26 \mathrm{a}$ & $22.14 \pm 2.11 \mathrm{a}$ & $26.35 \pm 1.94 \mathrm{a}$ & $27.06 \pm 2.85 \mathrm{a}$ \\
Hexane & $13.05 \pm 2.09 \mathrm{~b}$ & $10.94 \pm 0.44 \mathrm{~b}$ & $8.13 \pm 1.16 \mathrm{c}$ & $5.13 \pm 1.92 \mathrm{c}$ \\
Ethyl & $7.71 \pm 2.51 \mathrm{c}$ & $5.74 \pm 0.38 \mathrm{c}$ & $3.02 \pm 1.15 \mathrm{~d}$ & $2.33 \pm 1.86 \mathrm{~d}$ \\
acetate & & & & \\
Methanol & $16.32 \pm 2.33 \mathrm{~b}$ & $13.94 \pm 1.88 \mathrm{~b}$ & $14.18 \pm 2.77 \mathrm{~b}$ & $13.94 \pm 0.28 \mathrm{~b}$ \\
Acetone & $13.18 \pm 2.84 \mathrm{~b}$ & $11.09 \pm 0.54 \mathrm{~b}$ & $9.81 \pm 0.33 \mathrm{c}$ & $6.55 \pm 1.13 \mathrm{c}$ \\
$\begin{array}{l}\text { Fumigant toxicity } \\
\text { Control }\end{array}$ & $25.40 \pm 0.0 \mathrm{a}$ & $23.19 \pm 0.55 \mathrm{a}$ & $22.95 \pm 1.4 \mathrm{a}$ & $23.42 \pm 1.3 \mathrm{a}$ \\
Hexane & $10.71 \pm 0.01 \mathrm{~b}$ & $9.99 \pm 1.20 \mathrm{~b}$ & $7.71 \pm 0.0 \mathrm{~b}$ & $1.03 \pm 0.4 \mathrm{c}$ \\
Ethyl & $9.15 \pm 0.03 \mathrm{~b}$ & $7.87 \pm 3.80 \mathrm{~b}$ & $6.09 \pm 0.30 \mathrm{~b}$ & $1.50 \pm 4.70 \mathrm{~b}$ \\
acetate & & & & \\
Methanol & $8.98 \pm 1.40 \mathrm{~b}$ & $8.12 \pm 1.80 \mathrm{~b}$ & $7.47 \pm 1.10 \mathrm{~b}$ & $6.20 \pm 2.20 \mathrm{~b}$ \\
Acetone & $9.99 \pm 2.50 \mathrm{~b}$ & $3.84 \pm 1.80 \mathrm{c}$ & $2.11 \pm 1.80 \mathrm{c}$ & $4.87 \pm 0.66 \mathrm{c}$ \\
\hline
\end{tabular}

Means within a column followed by different letters are significantly different $(P>0.05 \%)$, Tukey's Student's test (HSD)

highest dosage in acetone extract (10.26). However, none of the extracts were able to achieve complete suppression of adult emergence.

\section{Effect of Secamone afzelii extracts on percentage weight loss}

The percentage weight loss has a very highly significant variation following extracts and concentrations (Table 2). The highest weight loss (28.93 and 25.40\%) was recorded from untreated grains compared to treated grains, which have better protection that recorded a significant low 
weight loss. The percentage weight loss decreased with the increasing of the concentration level. The percentage weight loss among different concentrations of the S. afzelii leaf extracts was lowest in contact toxicity of wheat treated with $200 \mu \mathrm{l}$ ethyl acetate extract (2.33\%) followed by a hexane extract $(5.13 \%)$, while in fumigant toxicity, the lowest weight loss was recorded in hexane extract $(1.03 \%)$ and closely followed by ethyl acetate extract (1.50\%).

\section{Effect of Secamone afzelii extracts on percentage seed germination}

The results in Table 3 show a significant encouraging effect of $S$. afzelii extracts on the germination percentage of wheat grain after treatments and storage. A nonsignificant difference $(p<0.05)$ was observed between wheat grains in controls and the different concentrations of the extracts. The wheat grains treated with the lowest concentration of the extracts $(5 \mu \mathrm{l} / 20 \mathrm{~kg}$ wheat) and untreated (control) recorded more or less same germination rate. From this result, it is evident that seeds preserved with the different concentrations of the extracts did not lose their viability.

\section{Discussion}

Grain protectants play vital role in extending the storability of seeds to longer duration without appreciable loss in vigor and viability (Adesina et al. 2019a). The findings obtained in this study showed that $S$. afzelii extracts are effective as stored grains protectant against storage Table 3 Effect of Secamone afzelii extracts on percentage
seed germination

\begin{tabular}{|c|c|c|c|c|}
\hline \multirow{2}{*}{$\begin{array}{l}\begin{array}{l}\text { Contact } \\
\text { toxicity }\end{array} \\
\text { Treatments }\end{array}$} & \multicolumn{4}{|c|}{ Concentration $(\mu \mathrm{l})$} \\
\hline & 50 & 100 & 150 & 200 \\
\hline Control & $88.69 \pm 1.52 \mathrm{a}$ & $90.55 \pm 1.50 a$ & $91.69 \pm 0.44 a$ & $92.40 \pm 0.23 a$ \\
\hline Hexane & $91.95 \pm 1.20 \mathrm{a}$ & $89.11 \pm 1.17 a$ & $90.69 \pm 0.8 a$ & $93.40 \pm 0.38 a$ \\
\hline $\begin{array}{l}\text { Ethyl } \\
\text { acetate }\end{array}$ & $90.24 \pm 0.83 a$ & $91.40 \pm 1.83 a$ & $90.84 \pm 1.06 a$ & $90.25 \pm 2.06 a$ \\
\hline Methanol & $89.39 \pm 0.52 a$ & $93.40 \pm 1.62 \mathrm{a}$ & $90.69 \pm 0.48 a$ & $91.95 \pm 1.55 a$ \\
\hline Acetone & $92.24 \pm 1.48 a$ & $90.26 \pm 1.50 \mathrm{a}$ & $90.40 \pm 1.59 a$ & $91.66 \pm 1.88 a$ \\
\hline \multicolumn{5}{|c|}{ Fumigant toxicity } \\
\hline Control & $90.00 \pm 0.0 \mathrm{a}$ & $91.39 \pm 0.55 a$ & $90.00 \pm 1.4 a$ & $90.00 \pm 1.3 a$ \\
\hline Hexane & $90.30 \pm 0.33 a$ & $90.88 \pm 1.22 \mathrm{a}$ & $91.39 \pm 0.55 a$ & $92.00 \pm 0.74 a$ \\
\hline $\begin{array}{l}\text { Ethyl } \\
\text { acetate }\end{array}$ & $90.00 \pm 0.82 \mathrm{a}$ & $91.69 \pm 0.85 a$ & $89.69 \pm 0.94 a$ & $90.80 \pm 0.22 \mathrm{a}$ \\
\hline Methanol & $92.69 \pm 0.76 a$ & $91.30 \pm 1.88 a$ & $91.39 \pm 1.05 a$ & $90.00 \pm 0.38$ \\
\hline Acetone & $90.30 \pm 0.33 a$ & $90.69 \pm 0.57 a$ & $90.69 \pm 0.57 a$ & $90.00 \pm 0.38$ \\
\hline
\end{tabular}

Means within a column followed by different letters are significantly different $(P>0.05 \%)$, Tukey's Student test (HSD) insects in reducing grain damage and ultimately lower weight loss.

The present result complemented the outcomes of various study by researchers who assessed diverse plant extracts on most destructive stored product insect pests and establish that insects were highly vulnerable to contact and fumigant actions of botanical extracts and thus act as a good substitute to high continuing synthetic insecticides and fumigants for dealing with the insect pests in stored agricultural produce (Ukih et al 2010; Waseem et al 2019).

All the extracts treatments induced significant reduction in $R$. dominica adult emergence compared to the untreated control, although the extracts adult suppression potentiality varies within the treatments. Secamone afzelii ethyl acetate and hexane extracts were superior in reducing the $\mathrm{F} 1$ progeny emergence, and S. afzelii acetone extract was less effective compared to other extracts. The reduction in adult emergence observed in the treated grains might be as a result of the low survival rate of parent adult insect exposed to contact and fumigant toxicity, anti-oviposition, ovicidal and larvicidal properties of the tested extracts. This aligned with the findings of Tapondjou et al. (2002); Adesina et al. (2011); Adesina and Ofuya (2015); Adesina et al. (2015a, b) who opined that the oviposition inhibition property of plant products on adult storage insects makes them laid fewer eggs and where eggs are hatched the plant products killed the larvae hatching from eggs laid on grains. Udo (2005) opined that there is a relationship between first filla adult insect emergence and parental death as well as the likely presence of oviposition restrictive. Decline in offspring emergence from grains treated with $S$. afzelii extracts might be as a result of early mortality of adult insect and fractional or complete hindrance of embryonic growth. The significant reduction of adult emergence obtained from the study could also be due to the reaction of the different bioactive compounds present in these extracts.

The findings obtained in this study agreed with the earlier reports that plant extracts could adequately protect stored wheat from attack of its major insect pest of $R$. dominica owing to its $\mathrm{F} 1$ progeny production significant suppression. The ability of a botanical to act as biopesticides is not only accessed by its ability to evoked adult mortality but by its capability to hinder offspring development in treated grains (Khoshnoud et al. 2008).

The reduction in seed damage as manifested in the low weight loss recorded could be due to the likely biochemical constituents present in S. afzelii extracts which invariably caused adult mortality, reduction of adult emergence, hindered insect developmental stages, insect feeding on stored grains and seed damage. The present results substantiate the findings of Govindan and Nelson 
(2008); Adesina and Ofuya (2015) and Chandrakala et al. (2013) who reported the reduction in weight loss of stored grains when treated with different plant products and that plant products may be a prospective source of biopesticide for use in pest control approaches in preservation of stored grains against insect attack. Adesina et al. (2019b) stated that substantial infestation and associated grains damage and weight loss noted from the untreated grains evidently showed that vulnerable grains recorded high F1 progeny emergence and predisposed the grains to increasing percentage seed damage and ultimately weight loss due to the unhindered feeding, developmental and metabolic activities of the insects within the stored grains. The outcome of this study tallies with Adesina et al (2011); Adesina et al (2012); Adesina and Mobolade-Adesina (2016) who stated that postharvest weight loss of stored grains correlated with adult emergence inhibition rate.

Several botanical pesticides have been reported to affect the seed germination and seedling growth from treated seeds (Bell 1994; De Groot 1996; Seignobos 2002). The seeds used for germination test in this study were not damaged nor showed evidence of adult exit holes, though they could contain the hidden immature stages of weevil that could destroy the parts of seed embryo. However, in the present investigation, S. afzelii extracts did not harmfully affect the sprouting of the treated wheat as the germination of treated wheat did not exhibit any significant difference compared to untreated wheat which shows that $S$. afzelii extracts do not exhibit any phytotoxic effects on the seed. This property of the extracts backs its safety for use in maintaining the quality of stored grain for seed purpose and controlling the stored beetle infestation. This study established previous reports that plant products could effectively protect stored grains against storage insects (Paul et al. 2009) and conserved seed viability without having any negative consequence on germination (Mishra and Dubey 1994; Keita et al. 2001; Kishore and Dubey 2002; Goudoungou et al. 2015; Danjumma et al. 2018; Tagne et al. 2018; Adesina et al 2019a, c).

\section{Conclusion}

In conclusion, the present study indicated that leaves extracts of $S$. afzelii demonstrated significant botanical insecticidal action in the protection of stored wheat grains by enhancing varying degrees of adult emergence inhibition, feeding deterrence and reduced grain damaged as well as weight loss. Also, the treatments did not show any noticeable adverse effects on the germination capacity of the wheat seeds. Therefore, leaves extracts of $S$. afzelii can be utilized as a green insecticide substitute to conventional synthetic insecticides and fumigants in the control of insect infestation and preservation of stored grain quality. The plant is readily and widely available in many agro-ecological zones of Nigeria and used in the treatment of many aliments in folk medicine. Identification of the bioactive chemicals responsible for the S. afzelii extracts insecticidal activity and stored grains quality preservation should be a speedy research focus. Also, the toxicity of the plant extracts on albino rats should be evaluated.

\section{Abbreviations \\ ANOVA: Analysis of variance; HSD: Honest significant difference; CRD: Com- pletely Randomized Design.}

\section{Acknowledgements}

The authors acknowledged the research grant received from Tertiary Education Trust Fund (TETFund), Nigeria, for the study under the Institution-Based Research.

\section{Authors' contributions}

JMA conceived, designed and carried out the experiment and prepared the draft manuscript, and ATBA contributed to experiment conception and design, carried out statistical analysis and interpretation of data and proofreaded the manuscript. All authors read and approved the final manuscript.

\section{Funding}

The fund for the study was provided by Tertiary Education Trust Fund (TETFund), Nigeria, under the Institution-Based Research.

\section{Availability of data and materials}

Sharing of data is not applicable.

\section{Declarations}

Ethics approval and consent to participate Not applicable.

\section{Consent for publication}

Not applicable.

\section{Competing interests}

The authors have no competing interests to report.

Received: 2 October 2020 Accepted: 22 February 2021

Published online: 04 March 2021

$$
\begin{aligned}
& \text { References } \\
& \text { Adesina JM, Mobolade-Adesina TE (2016) Tolerance activities of Callasobru- } \\
& \text { chus maculatus (F.) (Coleoptera: chrysomelidae) against Secamone afzelii } \\
& \text { (Schult) K. Schum Leaf Extracts. Jordan J Agric Sci 12(4):1141-1154 } \\
& \text { Adesina JM, Mobolade-Adesina TE (2020) Callosobruchus maculatus (Fab.) } \\
& \text { Coleoptera: Chrysomelidae) infestation and tolerance on stored cowpea } \\
& \text { seeds protected with Anchomanes difformis (Blume) Engl. extracts. J Hort } \\
& \text { Post Harv Res 3(2):367-378. https://doi.org/10.22077/jhpr.2020.3145.1124 } \\
& \text { Adesina JM, Ofuya TI (2015) Oviposition deterrent and egg hatchability } \\
& \text { suppression of Secamone afzelii (Schult) K. Schum Leaf Extracts on Cal- } \\
& \text { lasobruchus maculatus (Fabricus) (Coleoptera: Chrysomelidae. J Jordan } \\
& \text { Biol Sci 8(2):95-100 } \\
& \text { Adesina JM, Afolabi LA, Aderibigbe ATB (2011) Efficacy of Senna occidentalis } \\
& \text { leaves powder on oviposition, hatchability of eggs and emergence of } \\
& \text { Callosobruchus maculatus (Fab.) on treated cowpea seeds. South Asian J } \\
& \text { Exp Biol 1(3):168-171 }
\end{aligned}
$$


Adesina JM, Ofuya TI, Afolabi LA (2012) Insecticidal activity of Secamone afzelii (Schult) K. Schum powder in the control of Stiphilous zeamais (Mots) (Coleoptera: Curculionidae). J Agric Tech 8(1):117-124

Adesina JM, Ngaihlun T, Rajashekar Y (2015a) Efficacy of Clerodendrum capitatum and Phyllantus fraternus leaves powder on seed beetles of stored maize and cowpea. J Crop Prot 4(4):655-665

Adesina JM, Jose AR, Rajashaker Y, Afolabi LA (2015b) EntomoToxicity of Xylopia aethiopica and Aframomum meleguta in Suppressing Oviposition and Adult Emergence of Callasobruchus maculatus (Fabricus) (Coleoptera: Chrysomelidae) infesting stored cowpea seeds. Jordan J Biol Sci 8(4):263-268

Adesina JM, Chanu HD, Singh KD, Devi TB, Singh NI, Raghavendra A, Sahoo D, Rajashekar Y (2018) Chemical composition, toxicity and biochemical efficacy of Phyllantus fraternus against major three stored grain pests. Ann Exp Biol 6(1):1-9

Adesina JM, lleke KD, Rajashekar Y (2019a) Eugenia aromatica O. Berg and Afromomum melegueta K. Schum botanical entomocides as possible synergetic protectant against Callosobruchus maculatus (Fabricus) (Coleoptera: Chrysomelidae) infestation on stored cowpea (Vigna unguiculata (L.) Walp.). Herbal Polonica 65(2):1-13. https://doi.org/10.2478/ hepo-2019-0008

Adesina JM, Rajashekar Y, Ofuya TI, Ashamo MO, lleke KD, Mobolade-Adesina TE (2019b) Seed protectant potential of Mitracarpus villosusand Phyllanthus fraternusextracts on germinative capability of stored food grains. Int J Hort Sci 25(3-4):7-10. https://doi.org/10.31421/IJHS/25/3-4/2914

Adesina JM, Raghavendra A, Rajashekar Y, Ofuya TI (2019c) Potential use of Clerodendrum capitatum extracts and its formulation for control of three major stored-product beetles. Food Qual Safety 20:1-7. https://doi. org/10.1093/fqsafe/fyz018

Adesina JM, Rajashekar Y, Ofuya TI (2020) Potentiality and chemical composition of Bridelia micrantha (berth) extracts and its fractions as biofumigant against economically important stored grain insect pests. J Hort PostHarv Res 3(1):61-72. https://doi.org/10.22077/jhpr.2019.2446.1058

Bell A (1994) Emploi des substances végétales comme produits de protection des stocks contre le grand capucin du grain (Prostephanus truncatus) et autres ravageurs. GTZ Eschborn Allemange 12:60-98

Chandrakala A, Reni Prabha A, Chitra D, Muralidharan S, Saravanababu S (2013) Toxic effect of neem powder (Azadirachta indica) against Callosobruchus chinensis infestation (Bruchidae: Coleoptera) on the green gram (Vigna radiata) seeds. Int J Pure Appl Zool 1:86-91

Danjumma BJ, Majeed Q, Yusuf M, Peni DN (2018) Effects of leaf powder of Citrus aurantifolia and Senna occidentalis on the development of maize weevil (Sitophilus zeamais Motschulsky, Coleoptera Curculionidae). J Entomol Zool Stud 6(2):2216-2221

De Groot I (1996) Protection des céréales légumineuses stockées. CTA Doc Agron 18:3-45

Demissie G, Tefera T, Tadesse A (2008) Efficacy of SilicoSec, filter cake and wood ash against the maize weevil, Sitophilus zeamais Motschulsky (Coleoptera: Curculionidae) on three maize genotypes. J Stored Prod Res 44:227-231

Goudoungou JW, Nukenine EN, Ndjonka D, Suh C, Cornel A (2015) Efficacy of diatomaceous earth and wood ash for the control of Sitophilus zeamais in stored maize. J Entomol Zool Stud 3(5):390-397

Govindan K, Nelson SJ (2008) Effect of mixtures of plant powder against pulse beetle, Callosobruchus maculatus (F.) (Coleoptera: Bruchidae). J Plant Prot Environ 5:52-57

lleke KD (2021) Responses of two plant-derived bioinsecticides as protectants of smoke-dried catfish, Clarias gariepinus [Pisces: Clariidae] against hide beetle, Dermestes maculatus (De Geer) [Coleoptera: Dermestidae]. Bull Natl Res Cent 45:28. https://doi.org/10.1186/s42269-020-00470-1

lleke KD, Adesina JM, Obajulaye EO (2016) Synergetic effects of Eugenia aromatic and Afromomum melegueta botanical entomicides as protectants of maize grains. J Biol Res 89(5917):33-39

Keita SM, Vincent C, Schmit JP, Arnason JT, Belanger A (2001) Efficacy of essential oil of Ocimum basilicum L. and O. gratissimum L. applied as an insecticidal fumigant and powder to control Callosobruchus maculatus (Fab.) (Coleoptera: Bruchidae). J Stored Prod Res 37:339-349

Kestenholz C, Stevenson BPC (2007) Comparative study of field and laboratory evaluations of the ethnobotanical Cassia sophera L. (Leguminosae) for bioactivity against the storage pests Callosobruchus maculatus (F.) (Coleoptera: Bruchidae) and Sitophilus oryzae (L.) (Coleoptera: Curculionidae). J Stored Prod Res 43:79-86

Khaliq A, Nawaz A, Ahmad HM, Sagheer M (2014) Assessment of insecticidal potential of medicinal plant extracts for control of maize weevil, Sitophilus zeamais Motschulsky (Coleoptera: Curculionidae). Basic Res J Agric Sci Rev 3(11):100-104

Khan I, Afsheen S, Din N, Khattak S, Khalil SK, Lou YHY (2010) Appraisal of different wheat genotypes against angoumois grain moth, Sitotroga ceralella (Oliv). Pak J Zool 42:161-168

Khoshnoud H, Ghiyasi M, Amimia R, Fard SS, Tajbakhsh M, Salehzadeh H et al (2008) The potentials of using inject properties of medicinal plants against insect pests. Pakistan J Biol Sci 11:1-5

Kishore N, Dubey NK (2002) Fungitoxic potency of some essential oils in management of damping-off diseases in soil infested with Pythium aphanidermatum and $P$. debaryanum. Indian J For 25:463-468

Mishra AK, Dubey NK (1994) Evaluation of some essential oils for their toxicity against fungi causing deterioration of stored food commodities. Appl Environ Microbiol 60:1401-1405

Ntonifor NN, Oben EO, Konje CB (2010) Use of selected plant-derived powders and their combinations to protect stored cowpea grains against damage by Callosobruchus maculatus. ARPN J Agric Biol Sci 5(5):13-21

Parkin EA (1956) Stored product entomology (the assessment and reduction of losses caused by insects to stored food stuffs). Ann Rev Entomol 1:233-240

Paul UV, Lossini JS, Edwards PJ, Hilbeck A (2009) Effectiveness of products from four locally grown plants for the management of Acanthoscelides obtectus (Say) and Zabrotes subfasciatus (Boheman) (both Coleoptera: Bruchidae) in stored beans under laboratory and farm conditions in Northern Tanzania. J Stored Prod Res 45(2):97-107

Seignobos C (2002) Stratégies de conservation du grain. Atlas de la province d'Extrême-Nord Cameroun, p. 12

Tagne GF, Elias NN, Rigobert T, Jean WG, Daniel K, Vandi T, Cornel A (2018) Use of cameroonian Hemizygia welwitschii Rolfe-Ashby (Lamiaceae) leaf powder against Callosobruchus maculatus and Sitophilus zeamais. J Entomol Zool Stud 6(4):1261-1269

Tapondju LA, Alder A, Bonda H, Fontem DA (2002) Efficacy of powder and oil from Chenpodium ambrosioides leaves as post-harvest grain protectants against six stored products beetles. J Stored Prod Res 38:395-402

Tesfu F, Emana G (2013) Evaluation of Parthenium hysterophorus L. powder against Callosobruchus chinensis L. (Coleoptera: Bruchidae) on chickpea under laboratory conditions. Afri J Agric Res 8:5405-5410

Udo IO (2005) Evaluation of the potential of some local spices as stored grain protectants against the maize weevil Sitophilus zeamais Motsch. (Coleoptera: (urculionidae). J Appl Sci Environ 9:165-168

Ukih DA, Birkett MA, Bruce TJA, Allan EJ, Pickett JA, Mordue AJ (2010) Behavioural responses of the maize weevil Sitophilus zeamais to Host (maize grain) and non-host plant volatiles. Pest Manag Sci 66:44-50

Waseem K, Sajjad A, Muhammad S, Abdur R, Hayat Z, Abdul L, Taimur K, Muhammad A, Ateeq UR (2019) Repellency evaluation of botanical extracts against Lasioderma serricorne (Anobiidae: Coleoptera) under laboratory condition. J Entomol Zool Stud 7(1):479-481

\section{Publisher's Note}

Springer Nature remains neutral with regard to jurisdictional claims in published maps and institutional affiliations. 